\title{
The ERC Mechanism and the Formation of Abnormal Product in the Stevens Rearrangement
}

\author{
Soumendranath Bhakat* \\ Nutanpalli, P.O. Suri \\ Dist. Birbhum \\ West Bengal, Pin: 731101 INDIA
}

Received: July 28, $2011 \quad$ Accepted October 30, 2011

\begin{abstract}
To explain the new abnormal product of the Stevens Rearrangement which is not explainable by different existing mechanisms like "radical pair mechanism"; "ionic pair mechanism", I proposed a new mechanism scheme entitled the ERC (Elimination Recombination Coupling) mechanism and a new abnormal product of the Stevens Rearrangement. This mechanism also maintains parity between the "radical pair mechanism" and the "ionic pair mechanism."
\end{abstract}

I. INTRODUCTION

For more than a decade various workers [1-4] have done several projects to determine the mechanism of the Stevens Rearrangement. The most recently accepted mechanism for this reaction is the radical pair mechanism which is based on the observation that came from CIDNP (Chemically Induced Dynamic Nuclear Polarisation) [5-7]. In many cases CIDNP, isotope tracer studies, and stereochemical probes also give the results compatible with the elimination-recombination mechanism provided by Johnstone and Stevens (1955) [1] and with the mechanism provided by Hauser and Kantor (1951) [2]. So it is hard to say that the radical pair mechanism is correct. This research study reports on a new abnormal product in the Stevens Rearrangement whose formation is not explainable with either the radical pair mechanism or by the ionic pair mechanism. A new mechanism scheme to explain the formation of both normal and abnormal product is discussed, one which not only supports the formation of the abnormal product but also maintains parity between the radical pair mechanism and the ionic pair mechanism proposed by Johnstone and Stevens [1].

\section{MATERIALS AND METHODS}

The Stevens Rearrangement in general can be represented as shown in Figure 1, and the Retro synthetic analysis for the formation of Compound $l$ is seen in Figure 2. The quaternary salt Compound I is obtained by refluxing the base (1 mol.) with bromoacetophenone $(1 \mathrm{~mol}$.) in benzene solution for 1.5 to 2 hours in 86 atmp at avg. $30^{\circ} \mathrm{C}$ laboratory condition.

*Email: soumendranath2009@gmail.com

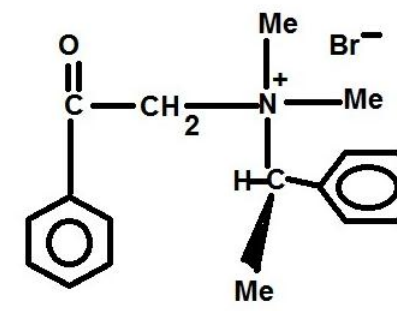

Compound I
Compound II

(Normal Product)

Figure 1. The Stevens Rearrangement. 


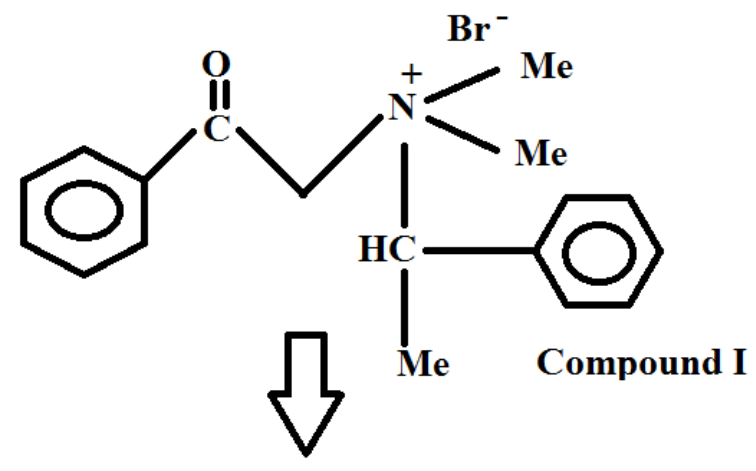<smiles>O=C(CBr)c1ccccc1</smiles><smiles>CC(c1ccccc1)N(C)C</smiles>

Figure 2. Retro synthetic analysis for the formation of Compound I.

The bromide was recrystallized from alcohol-ether .Reduction of the salts was carried out in hot aqueous solution by an excess of $\mathrm{Na}-\mathrm{Hg}$.

Formation of Compound II
(Normal Rearrangement product)

Compound $I$ is heated inside a microwave oven (Model: IFB 20SC2 20L Convection) regulating temperature 105$110^{\circ} \mathrm{C}$ with excess of $15 \% \mathrm{NaOH}$ solution for 1.5 to 2 hours. The oily product (Compound II) solidifies on cooling and is recrystallized from aqueous methyl alcohol. Yield is $86-89 \%$.

Compound II forms colorless leaflets m.p. $83-85^{\circ} \mathrm{C}$ (measured using Buchi melting point apparatus, Model B$545, A C$ input $230 \mathrm{~V}$ ), moderately easily soluble in methyl alcohol and readily soluble in benzene or light petroleum (Found: C, 82.4, 82.5; H, 8.2, 8.2;N,5.43 $\mathrm{M}$, cryscopic in benzene, 266. $\mathrm{C}_{18} \mathrm{H}_{21} \mathrm{ON}$ requires $\mathrm{C}, 82.3 ; \mathrm{H}, 8.01 \%$; $\mathrm{N}, 5.24 ; \mathrm{M}$, 267). The substance is slightly volatile in stream and slowly resinifies on keeping. It does not appear to react with hydroxylamine, semicarbazide, or $p$ nitrophenylhydrazine and is comparatively stable towards acid permanganate which obeys all the characteristics of the normal rearrangement product of the Stevens Rearrangement. All the properties of this product Compound I/ match the criteria of the normal rearrangement product [8]. b. Formation of the abnormal product (Compound III)

Compound III has a yield of $8-8.5 \%$. M, $324, \mathrm{C}_{20} \mathrm{H}_{24} \mathrm{O}_{2} \mathrm{~N}_{2}$. Found $\mathrm{C}, 75.9 \%, 75.8 \%$; $\mathrm{H}, 6.9,6.9 \%$; $\mathrm{M}$, cryscopic in benzene 323. Requires $\mathrm{C}, 76 \% ; \mathrm{H}, 7 \% ; \mathrm{M}, 324$, $\mathrm{C}_{20} \mathrm{H}_{24} \mathrm{O}_{2} \mathrm{~N}_{2}$. Compound III is very less volatile in steam, slowly resinifies in keeping, doesn't react with hydroxylamine, semicarbazide or $\mathrm{p}$-nitrophenyl hydrazine, and is very much stable in $\mathrm{KMNO}_{4}$ solution.

\section{RESULTS AND DISCUSSION}

The formation of abnormal product Compound III can't be explainable with the help of radical pair mechanism nor with the ionic pair mechanism. Hence I developed a new scheme which not only supports the formation of the abnormal product but also shows the formation of the normal product, Compound II. There are three main steps in this mechanism scheme, elimination, recombination, and coupling. As these three steps are involved in this mechanism, this scheme is named the Elimination-RecombinationCoupling Mechanism (ERC mechanism). It is outlined in Figure 4.

In this scheme due to the formation of Ph-C $-\mathrm{H}-\mathrm{CH}_{3}, \mathrm{Ph}-\mathrm{C}^{+} \mathrm{H}-\mathrm{CH}_{3}$, the coupling product R-R, Compound IV (shown in Figure 5) is formed. 


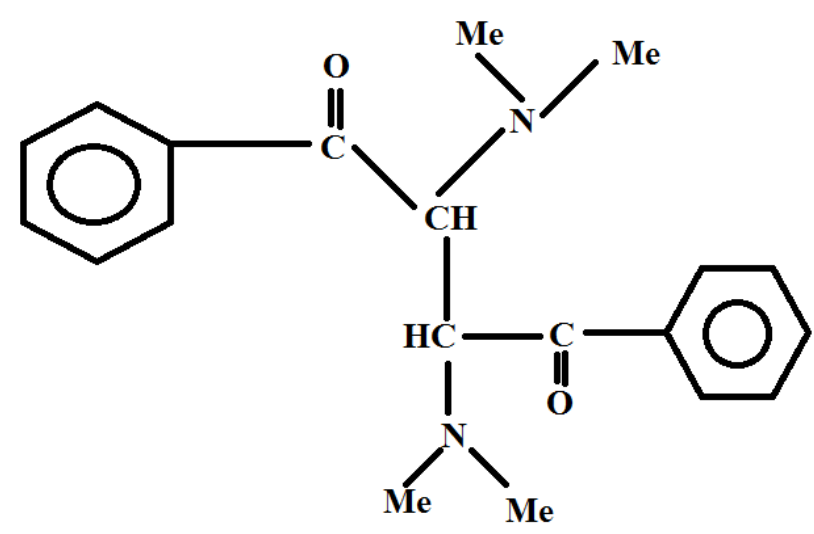

Abnormal product Compound III

Figure 3. Formation of the abnormal product (Compound III).

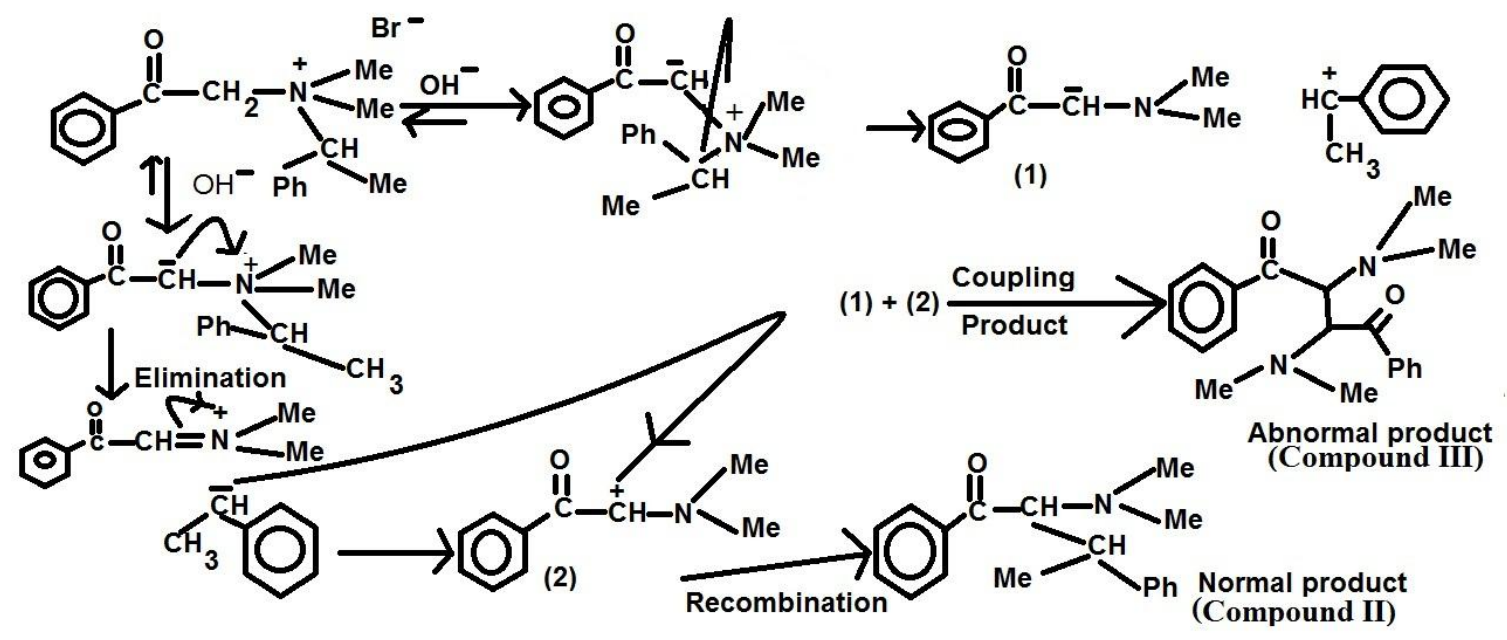

Figure 4. The ERC Mechanism.

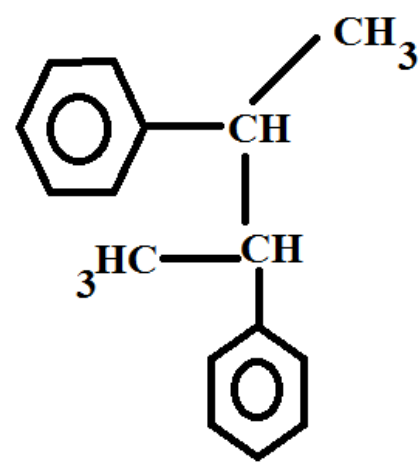

Figure 5. Compound IV (Coupling abnormal product). Note: The positions of the molecules are not drawn for stereochemical viewing. 

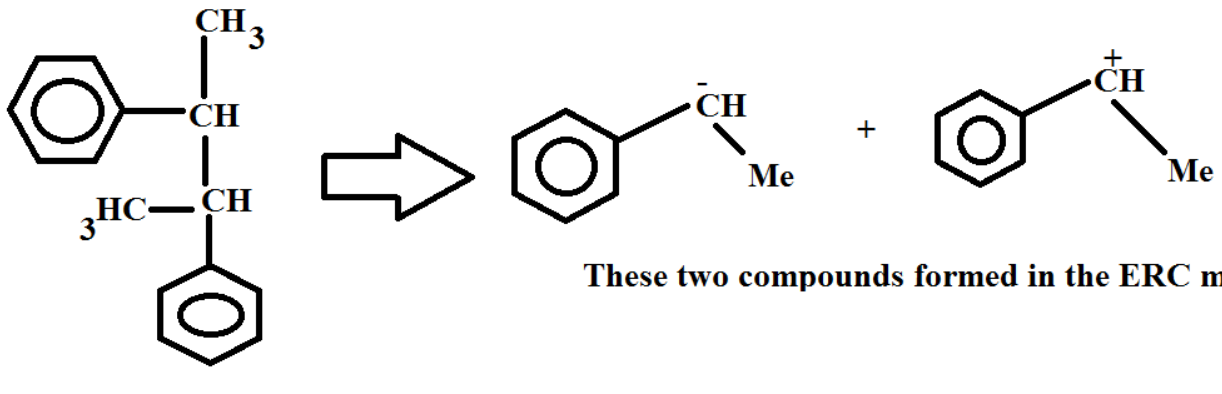

Compound IV

Figure 6. Retrosynthetic Analysis for the synthesis of Compound IV.

The yield for Compound IV is 1.56-2\%. Specifics: Compound IV M, 210, required $\mathrm{C}, 91.0, \mathrm{H}, 8 \%$; found ${ }^{\circ} \mathrm{C}$ $90.8,90.9 ; \quad H, 7.9,7.9 ; \quad M$, cryscopic in benzene, 209 is insoluble in water but soluble in typical organic solvents. The Compound IV Molecular formula is $\mathrm{C}_{16} \mathrm{H}_{18}$ with approximate density $1.54 \mathrm{~g} / \mathrm{cm}^{3}$; and approximate boiling point $289 \mathrm{C}$, where this data is calculated at near $30.9^{\circ} \mathrm{C}$ and $150 \mathrm{kPa}$, and the boiling point is measured using VEEGO instruments.

As Compound IV is formed, one can imagine that $\mathrm{Ph}-\mathrm{C}-\mathrm{H}-\mathrm{CH}_{3}, \mathrm{Ph}-\mathrm{C}^{+} \mathrm{H}-\mathrm{CH}_{3}$ should be formed (Figure 6), which is explainable by the ERC mechanism scheme (Figure 4). This proves that the ERC mechanism is very much significant in the formation of normal product and abnormal products because it not only satisfies the formation of coupling and abnormal products but also the formation of normal product, which the radical pair mechanism can't successfully manage because in many cases it will also be explainable by the ionic pair mechanism.

\section{ACKNOWLEDGEMENTS}

Lots of people must be acknowledged. First of all Prof. Brian Yates of the School of Chemistry, University of Tasmania, Private Bag 75, Hobart TAS 7001, Australia, for evaluating and helping me via suggestions. I also want to thank to Dr. Roald Hoffmann of the Department of Chemistry and Chemical Biology, Cornell University, Baker Laboratory, Ithaca, NY 14853-1301, USA, for his constant encouragement and review my work. Last, but not the least, I owe thanks to Dr. Somnath Bhakat and to all my family members from whom I got the interest, and to my teachers Mr. Ashis Chakraborty and Mr. Shasti. K. Das for their encouragement, and to all my friends at BIT, Mesra, for their healthy criticism.

\section{REFERENCES}

1. R.A.W. Johnstone and T.S.Stevens, J. Chem. Soc., 4487 (1955).

2. C.R. Hauser and S.W. Kantor, J. Am. Chem. Soc., 73:1437 (1951).

3. U. Schollkopf et. al., Tet. Letters, 3415 (1969).

4. J.J. Zang and G.B. Schuster, J. Org. Chem., 53:716 (1988).

5. U. Schollkopf; U. Ludwig, Chem. Ber.,1968, 101, 2224.

6. W. D. Ollis; M. Rey; I. O. Sutherland, J. Chem. Soc. Perkin Trans. 1. 1983, 1009 and 1049.

7. A. R. Leply and G. R. Closs, Eds., Chemically Induced Magnetic Polarization (Wiley, New York, 1973) pp.323-384.

8. A. Campbell, A. H. J. Houston and J. Kenyon,J. Chem. Soc. 93 (1947).

\section{APPENDIX: Supplementary Information}

The NMR shift data for Compounds III and IV (Figures 3 and 5) are shown below.

The NMR data of Compound III: ${ }^{1} \mathrm{H} \mathrm{nmr}$ $2.326(1,3 \mathrm{H}), 2.326(2,3 \mathrm{H}), 2.326(3,3 \mathrm{H})$, $2.326(4,3 \mathrm{H}), 7.662(7,1 \mathrm{H}$, tdd, J=7.243, $\mathrm{J}=1.469, \quad \mathrm{~J}=1.468), \quad 7.662 \quad(8, \quad 1 \mathrm{H}, \quad \mathrm{tt}$, $\mathrm{J}=7.368, \mathrm{~J}=1.468), 7.559(9,1 \mathrm{H}$, dddd, $\mathrm{J}=8.454, \quad J=7.243, \quad J=1.020, \quad J=0.000)$, $7.560(10,1 \mathrm{H}$, dddd, $\mathrm{J}=8.454, \mathrm{~J}=7.243$, $\mathrm{J}=1.027, \mathrm{~J}=0.000), 7.559(11,1 \mathrm{H}$, dddd, 
$\mathrm{J}=8.456, \quad \mathrm{~J}=7.368, \quad \mathrm{~J}=1.031, \quad \mathrm{~J}=0.000)$, $7.559(12,1 \mathrm{H}$, dddd, $\mathrm{J}=8.455, \mathrm{~J}=7.368$, $\mathrm{J}=1.036, \mathrm{~J}=0.000), 7.948(13,1 \mathrm{H}$, dddd, $\mathrm{J}=8.454, \quad \mathrm{~J}=1.468, \quad \mathrm{~J}=1.027, \quad \mathrm{~J}=0.000)$, $7.948(14,1 \mathrm{H}$, dddd, $\mathrm{J}=8.454, \mathrm{~J}=1.469$,
$\mathrm{J}=1.020, \mathrm{~J}=0.000), 7.966(15,1 \mathrm{H}, \mathrm{dddd}$, $\mathrm{J}=8.456, \quad \mathrm{~J}=1.848, \quad \mathrm{~J}=1.468, \quad \mathrm{~J}=1.036)$, $7.948(16,1 \mathrm{H}$, dddd, $\mathrm{J}=8.455, \mathrm{~J}=1.848$, $\mathrm{J}=1.468, \quad \mathrm{~J}=1.031), \quad 4.246 \quad(21,1 \mathrm{H}, \mathrm{d}$, $\mathrm{J}=0.000), 4.246(22,1 \mathrm{H}, \mathrm{d}, \mathrm{J}=0.000)$.

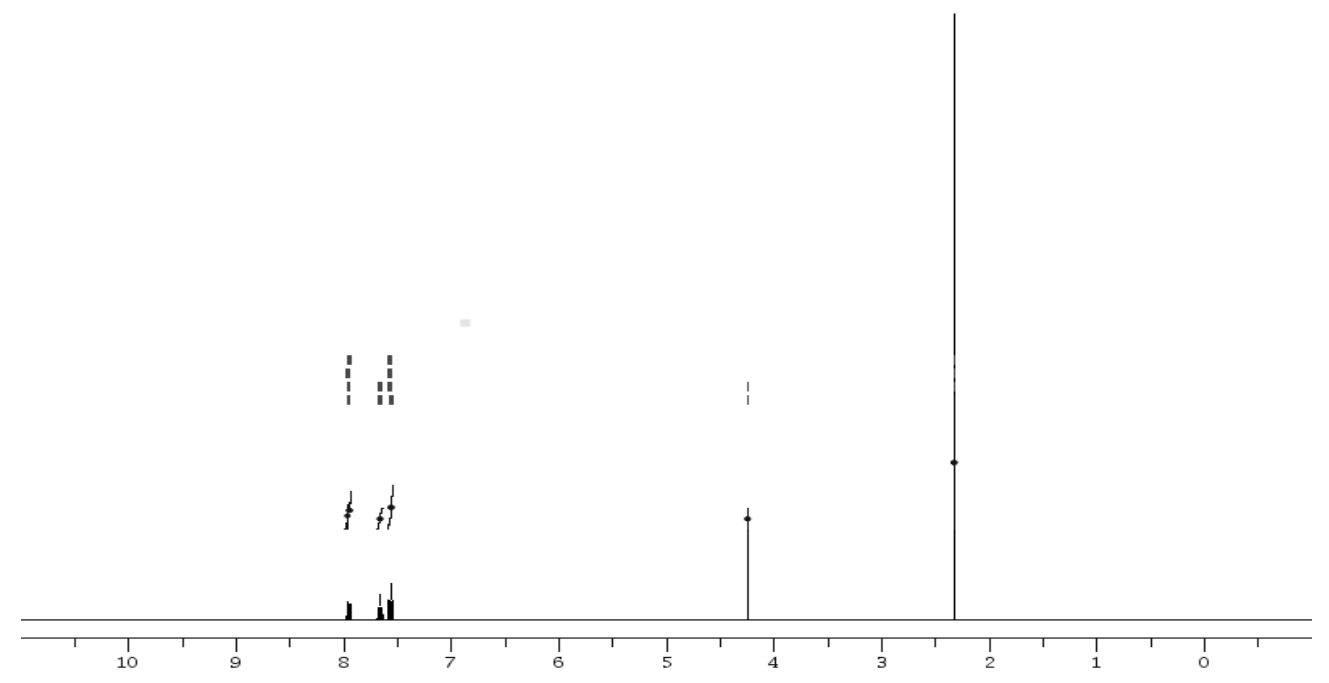

Figure A1. The NMR data for Compound III.

The NMR data for Compound IV: ${ }^{1} \mathrm{H}$ nmr $1.084(1,3 \mathrm{H}, \mathrm{d}, \mathrm{J}=6.700), 1.084(2,3 \mathrm{H}, \mathrm{d}$, $\mathrm{J}=6.700), \quad 7.151 \quad(3, \quad 1 \mathrm{H}, \quad \mathrm{tt}, \quad \mathrm{J}=7.727$, $\mathrm{J}=1.266), \quad 7.151 \quad(4, \quad 1 \mathrm{H}, \quad \mathrm{tt}, \quad \mathrm{J}=7.727$, $\mathrm{J}=1.266), 7.242(5,1 \mathrm{H}$, dddd, $\mathrm{J}=7.828$, $\mathrm{J}=7.727, \mathrm{~J}=3.926, \mathrm{~J}=0.000), 7.242(6,1 \mathrm{H}$, dddd, J=7.828, J=7.727, J=3.913, $\mathrm{J}=0.000), 7.242(7,1 \mathrm{H}$, dddd, $\mathrm{J}=7.828$, $\mathrm{J}=7.727, \mathrm{~J}=3.913, \mathrm{~J}=0.000), 7.242(8,1 \mathrm{H}$, dddd, J=7.828, J=7.727, $\mathrm{J}=3.926$,
$\mathrm{J}=0.000), 7.154(9,1 \mathrm{H}$, dddd, $\mathrm{J}=7.828$, $\mathrm{J}=3.913, \mathrm{~J}=1.266, \mathrm{~J}=0.000), 7.154 \quad(10$, $1 \mathrm{H}$, dddd, $\mathrm{J}=7.828, \mathrm{~J}=3.926, \mathrm{~J}=1.266$, $\mathrm{J}=0.000), 7.154(11,1 \mathrm{H}$, dddd, $\mathrm{J}=7.828$, $\mathrm{J}=3.926, \mathrm{~J}=1.266, \mathrm{~J}=0.000), 7.154 \quad(12$, $1 \mathrm{H}$, dddd, $\mathrm{J}=7.828, \mathrm{~J}=3.913, \mathrm{~J}=1.266$, $\mathrm{J}=0.000), 3.082(15,1 \mathrm{H}, \mathrm{qd}, \mathrm{J}=6.700$, $\mathrm{J}=0.000), 3.082(16,1 \mathrm{H}, \mathrm{qd}, \mathrm{J}=6.700$, $\mathrm{J}=0.000$ ).

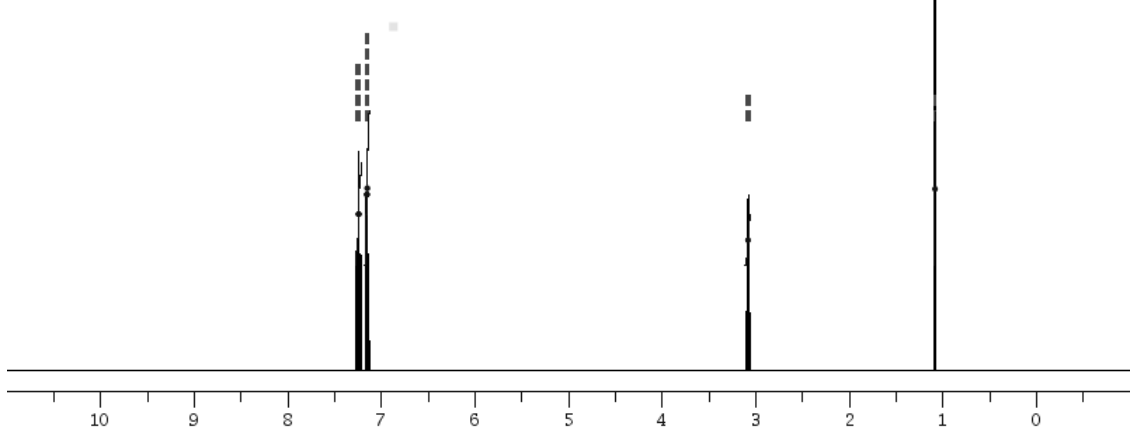

Figure A2. The NMR data for Compound IV. 


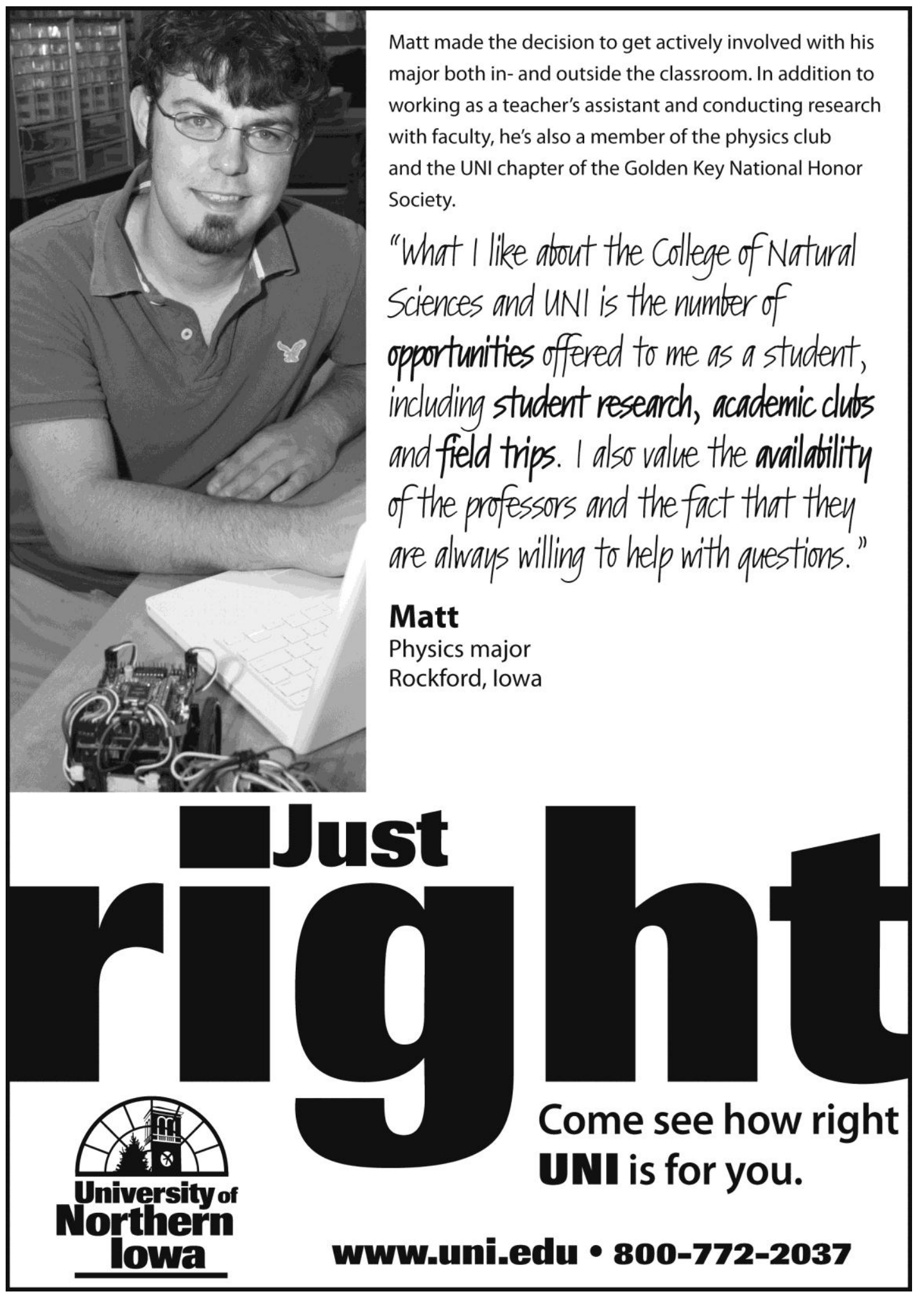

